\title{
A CONVERGÊNCIA MIDIÁTICA E AS MUDANÇAS COMPORTAMENTAIS NO CONSUMO DO MERCADO DE NICHO: NETFLIX E A “DESMATERIALIZAÇÃO” DOS PRODUTOS"
}

\author{
MEDIA CONVERGENCE AND BEHAVIORAL CHANGES OF NICHE \\ MARKET CONSUMPTION: NETFLIX AND THE "DEMATERIALIZATION" \\ OF PRODUCTS
}
LA CONVERGENCIA DE MEDIOS Y LOS CAMBIOS COMPORTAMENTALES DEL CONSUMO DEL MERCADO DE NICHO: NETFLIX Y LA "DESMATERIALIZACIÓN" DE LOS PRODUCTOS

Letícia Hermann UTP letícia_herrmann@hotmail.com

\section{Resumo}

Este estudo articula as formas de produção e consumo como maneira de conquistar mercados de nicho. Com o crescimento da utilização da internet, surgem tendências de mercado com produtos adaptados ao consumo desmaterializado que a rede proporciona. Como resultado, essa reflexão aponta a internet como ferramenta auxiliar na aquisição de produtos, cuja ideia central remete a não necessidade do contato material criando um hábito de consumo sustentável em mercados de nicho, apresentado neste artigo pela pesquisa empírica com consumidores, que abordou o conhecimento e o uso da Netflix. A discussão teórica apoiou-se na mobilidade e sociedade em redes (CASTELLS, 2009), democratização do consumo (CANCLINI, 1995; MILLER 1998; BAUDRILLARD, 2003), mercado de nicho (ANDERSON, 2009) e na convergência (JENKINS, 2009).

Palavras-chave: Desmaterialização dos Produtos; Convergência Midiática; Mercado de Nicho.

\begin{abstract}
This study articulates forms of production and consumption as a way to conquer niche markets. With the growth of internet usage, new market trends arrise with products adapted to the dematerialized consumption that the network provides. As a result, this study reveals the internet as an auxiliary tool in the acquisition of products. The central idea is that physical contact is no longer needed, therefore, creating sustainable consumption in niche markets. This article is featured by empirical research with consumers, who acknowledged knowing and using Netflix. This theoretical discussion is based on the studies on mobility and social
\end{abstract}

\footnotetext{
${ }^{1} \mathrm{O}$ artigo apresentado teve como base estudo prévio apresentado no ENEC 2012.
} 
networks (CASTELLS, 2009), democratization of consumption (CANCLINI, 1995; MILLER 1998; BAUDRILLARD, 2003), niche market (ANDERSON, 2009) and convergence (JENKINS, 2009).

Key Words: Dematerialization of Products; Media Convergence; Niche Market.

\section{Resumen}

Este estudio articula las formas de producción y consumo como manera de conquistar mercados de nicho. Con el crecimiento de internet, surgen tendencias de mercado con productos adaptados al consumo desmaterializado que la red proporciona. A consecuencia, esa reflexión apunta la internet como herramienta auxiliar en la adquisición de productos, cuya idea central remite a la ausencia de necesidad de contacto material, creando una costumbre de consumo sostenible en mercados de nicho, presentada en este artículo a través de la investigación empírica con consumidores, que enfocó el conocimiento y uso de Netflix. La discusión teórica se respaldó en la movilidad y sociedad en redes (CASTELLS, 2009), democratización del consumo, (CANCLINI, 1995; MILLER 1998; BAUDRILLARD, 2003), el mercado de nicho (ANDERSON, 2009) y en la convergencia (JENKINS, 2009).

Palabras clave: Desmaterialización de los Productos; Convergencia de los Medios; Mercado de Nicho.

\section{1 - Introdução}

A cada ano novos produtos são lançados e diferentes desejos são criados para que os consumidores adquiram outros bens de consumo. No ano de 2010, rumores de que um aparelho seria lançado para mudar a forma de como nos comunicamos, eram propagados rapidamente em diversos países. A Apple, então, lança o Ipad, o primeiro tablet da empresa. Em menos de dois anos de seu lançamento, já podemos escolher entre os 3 tipos existentes de Ipad, com algumas diferenças tecnológicas, mas que no geral propiciam uma similaridade em sua funcionalidade, e esse é um dos inúmeros exemplo de produtos de consumo efêmero (LIPOVETSKY, 1987).

A produção desenfreada de novos produtos gera um descarte frequente dos mesmos, substituídos continuamente por outros, que nem sempre foram pensados considerando à preservação ambiental. Por outro lado, essa constante necessidade criativa mercadológica, faz 
com que empresas busquem alternativas diferenciadas em seus produtos, como é o caso da Netflix.

Embora nos Estados Unidos a Netflix já exista há algum tempo, aqui no Brasil o produto gradativamente conquista seu espaço no mercado, não só como bem de consumo, mas representando uma quebra de padrões culturais na forma de se consumir filmes e seriados.

A Netflix é uma empresa que oferece filmes e seriados digitalizados, com possibilidade de assisti-los em computadores, televisões e vídeo games. Neste processo, a indústria oferece a possibilidade de acesso aos filmes, sem a necessidade de contato físico com DVDs, fitas, embalagens ou papeis usados nos trâmites de empréstimo em locações. Temos aqui um exemplo de produto que consegue se manter sem o uso da loja física e da utilização de determinados recursos materiais para existir, além de estimular o download pago, prática que vem sendo discutida em decorrência dos processos da pirataria digital.

Consciente ou não, produtos como os ofertados pela empresa Netflix são responsáveis pela conservação ambiental, uma vez que contribuem para a desmaterialização de produtos, cujo descarte acontece rapidamente. O produto da indústria fílmica ganha espaço para contribuir com a responsabilidade social do planeta, sendo este mais um atributo de posicionamento de marca no mercado brasileiro, pois aos poucos, nos adaptamos a outros usos dos objetos na medida em que somos inserimos nas diferentes tecnologias, além da própria comodidade no processo de aquisição oferecida ao consumidor.

Este artigo abordará o comportamento do consumidor em relação às variações do mercado de nicho, da relação com a convergência midiática, do uso da internet e de suas variáveis no processo de consumo de produtos desmaterializados e na sustentabilidade propiciada ao meio ambiente proveniente dos novos tipos de consumo.

\section{2 - O Comportamento e o Consumo do Mercado de Nicho}

O consumo tem papel fundamental no processo cultural e de socialização, pois é através dele que indivíduos se inserem em contextos sociais, atribuindo um valor diferente aos objetos adquiridos. Para Baudrillard (2008), é possível a divisão do consumo em dois 
processos distintos, que consiste em: "significação e comunicação" e "classificação e diferenciação social”.

Processo de significação e de comunicação, baseado num código em que as práticas de consumo vêm inserir-se e assumir o respectivo sentido. $\mathrm{O}$ consumo revela-se aqui como sistema de permuta e equivalente de uma linguagem, sendo abordado neste nível pela análise estrutural. Processo de classificação e diferenciação social, em que os objetos/signos se ordenam, não só como diferenças significativas no interior de um código, mas como valores estatutários no seio de uma hierarquia. Nesta acepção, o consumo pode ser objeto de análise estratégica que determina o seu peso específico na distribuição dos valores estatutários (com a implicação de outros significantes sociais: saber, poder, cultura, etc.). (BAUDRILLARD, 2008, p.66)

O processo de "significação e comunicação" refere-se ao valor simbólico que o objeto carrega consigo, já o de "classificação e diferenciação social" é a leitura social, as diferenças associadas ao uso do objeto. Outros importantes fatores também são apontados por autores da área de consumo, mas o foco do tema é trazer a reflexão desse artigo, a luz de boas práticas mercadológicas, sob a ótica de um consumo moderno, prático, rentável e ao mesmo tempo sustentável. Iniciando a lógica do processo de consumo, temos de um lado os objetos e de outro os consumidores. Um objeto, por si só, possui significados próprios, mas esses são atribuídos pela própria indústria e pela sociedade que o consome.

Nunca se consome o objeto em si, os objetos manipulam-se sempre como signos que distinguem o indivíduo, quer filiando-o no próprio grupo tomado como referência ideal quer demarcando-o do respectivo grupo por referência a um grupo de estatuto superior. (BAUDRILLARD, 2006, p. 66)

A questão observada pelo autor, referindo-se a importância dos grupos, leva-nos ao entendimento do aglomerado de pessoas com gostos ou características em comum, no processo do estudo do consumo, o que incita o pensamento da existência dos mercados de consumo segmentados, por aproximação de gostos e atitudes. Cada vez mais se incorporam diferentes formas de mostrar os objetos às pessoas. O uso dos objetos depende da intenção de cada comprador, que pode ainda, dar um novo sentido ao bem adquirido. Existem variados exemplos de apropriações usadas pela indústria e consumidores, no que se refere à mudança na forma de consumo, como a que ocorre atualmente na indústria fílmica, por exemplo. 
Como produto mercadológico, os filmes, que antes eram projetados apenas em cinemas, passam a ocupar novos papeis no cenário de consumo. A proliferação das inúmeras telas, por meio de televisores, computadores, celulares e tablets, deixam o consumidor escolher em qual plataforma deseja consumir o produto audiovisual. Essas opções oferecidas pelas marcas aos consumidores desencadeiam a necessidade de um olhar mais pontual a quem consome os produtos. O uso do mercado de nicho aparece justamente dentro deste cenário, no qual é possível segmentarmos produtos por perfis pessoais, significando a passagem da mídia de massa ao planejamento de produtos direcionados a uma parcela potencial de consumo, ocasionando rentabilidade financeira e foco nas campanhas publicitárias.

A segmentação nas campanhas de marketing, indicada pelos estudos de comportamento do consumidor, vem sendo trabalhada por Kotler e Armstrong (1998), Solomon (2002) Mowen e Minor (2003), entre outros, porém o olhar de Anderson (2006) sobre o mercado de nicho nos diversos segmentos apresenta o cenário de uma "supersegmentação" no movimento da "Cauda Longa". A definição do autor consiste na venda de grande variedade de itens em pequenas quantidades, oferecendo produtos segmentados aos mercados de nicho, se contrapondo ao movimento do varejo que oferece pouca variedade de itens que vendem muito.

Cauda Longa é nada mais que escolha infinita. Distribuição abundante e barata significa variedade farta, acessível e ilimitada - o que por sua vez, quer dizer que o público tende a distribuir-se de maneira tão dispersa quanto as escolhas. Sob a perspectiva da mídia e da indústria do entretenimento dominantes, essa situação se assemelha a uma batalha entre os meios de comunicação tradicionais e a internet. Mas o problema é que, quando as pessoas deslocam sua atenção para veículos online, elas não só migram de um meio para o outro, mas também simplesmente se dispersam entre inúmeras ofertas. Escolha infinita é o mesmo que fragmentação máxima. (ANDERSON, 2006, p.179)

Temos então, com o olhar do mercado de nicho, a oportunidade mercadológica de adaptar e oferecer, cada vez mais, produtos direcionados a grupos sociais distintos. Separar o consumidor por classe social, gênero e idade, não é mais suficiente nas estratégias mercadológicas, pois "cada um de nós pertence a muitas tribos diferentes simultaneamente" (ANDERSON, 2006, p. 182). 
Os meios de comunicação ocupam papel de importância no processo de consumo, eles são o canal de informação entre os indivíduos e seus produtos, mas temos uma variação de relação entre eles com o uso da internet na sociedade contemporânea. Embora as televisões, rádios, jornais e revistas ofereçam canais para feedback à população, a internet é uma ferramenta ainda mais forte, se compararmos as questões de possibilidade de compartilhamento de informações de qualquer indivíduo para qualquer indivíduo, desde que tenha acesso à rede.

A internet vem mudando a forma com que nos relacionamos com o consumo, seja em número de produtos ofertados, pois todos podem vender e comprar sem a barreira física, segmentação e direcionamento dos conteúdos oferecidos, ou ainda, na mudança do processo de compra.

\section{3 - O Papel da Internet no Consumo e a Desmaterialização dos Produtos}

Pesquisa recente realizada pela FGV (Fundação Getúlio Vargas) divulgada em agosto de 2012 (EXAME, 2012), mostra que o Brasil está no ranking dos países com maior número de acesso à internet e celulares do mundo e esses acessos já representam 51,3\% do total da população brasileira. Considerando que mais da metade dos brasileiros já estão conectados, a internet torna-se, cada vez mais, um meio de comunicação de relevância nos contextos de consumo.

Com a disponibilização dos diversos canais de acesso à internet e a proliferação desse produto por inúmeras empresas, ocorre maior facilidade na aquisição de aparelhos por diferentes consumidores, estimulados pela convergência. "A convergência midiática é mais que uma mera mudança tecnológica. A convergência altera a relação entre as tecnologias existentes, as indústrias, os mercados, os gêneros e o público.” (JENKINS, 2008, p.26). Os múltiplos aparelhos oferecidos facilitam a acessibilidade da população à informação e é a própria possibilidade de opiniões e integração propiciadas pela rede. A sociedade estruturada em redes facilita a comunicação; é a mobilidade na vida cotidiana.

As redes de comunicação digital são a coluna vertebral da sociedade em rede, tal como as redes de potência (ou redes energéticas) eram as infraestruturas sobre as quais a sociedade industrial foi construída (...). $\mathrm{Na}$ 
verdade, a sociedade em rede manifesta-se de diversas formas, conforme a cultura, as instituições e a trajetória histórica de cada sociedade (...). Além disso, a comunicação em rede transcende fronteiras, a sociedade em rede é global, é baseada em redes globais. (CASTELLS, 2005, p.08)

A rede de conexão da internet facilita a via de mão dupla da comunicação: temos provedores e receptores de informação simultaneamente. O poder da comunicação, por sua vez, torna-se cada vez mais descentralizado e os grupos sociais ganham novas formas de relacionamento e integração, no qual seus vínculos são apresentados aos demais grupos, ao exemplo da constituição da rede social Facebook.

Por outro lado, esse processo também propicia a inclusão social de diferentes camadas da população, que, gradativamente, vão tendo contato com os recursos da internet; sejam em computadores ou celulares. Para efeito de informação, hoje o Brasil possui 250,8 milhões de linhas ativas de celular (UOL, 2012), número superior à quantidade de habitantes do Brasil, divulgado no último censo (IBGE, 2010).

Baudrillard (2006) aponta a construção dos produtos firmados em grupos de pessoas, que por sua vez, são estimulados ao consumo pela comunicação e inclusão social. Outros fatores relevantes, citados por Barbosa (2004), são relacionados ao descarte de produtos. Quanto mais consumimos, mais produtos são desenvolvidos, e por se tornarem obsoletos, acabam sendo descartados, o que se relaciona diretamente com o fator tempo, pois o "tempo constitui uma mercadoria rara, preciosa e submetida às leis do valor de troca" (BAUDRILLAD, 2006, p.204). Quanto mais se produz ao longo do tempo, mais se descarta; um processo natural do consumo.

Outros resgates teóricos do consumo, apresentados por Barbosa (2004), indicam que na sociedade moderna de consumo existem outras implicações, referindo-se às discussões de Campbell (2000) nos estudos dessa área.

O espírito do consumidor moderno 'é tudo, menos materialista'. Se os consumidores desejassem realmente a posse material dos bens, se o prazer estivesse nela contido, a tendência seria a acumulação de objetos, não o descarte rápido das mercadorias e a busca por algo novo que possa despertar os mesmos mecanismos associativos". (BARBOSA, 2004, p. 53)

Todas estas mudanças, com o advento da internet, acarretaram em uma série de transformações na indústria dos bens de consumo. Empresas precisaram se adaptar ao cenário, 
novos produtos surgiram e outros foram adaptados e, por sua vez, desapareceram. Estamos vivendo em uma nova etapa de como se fazer marketing e propaganda. A relação que temos com o tempo também foi motivo de revisão estratégica, o mercado exige rapidez e os produtos são desenvolvidos para serem desejados pelos consumidores. Surge então, uma necessidade nova e desafiadora também para o meio ambiente, pelo uso contínuo de recursos naturais e pelo descarte dos próprios produtos que se tornaram obsoletos.

Na perspectiva de analisar o consumo versus a cultura, Miller (2007) aponta-o como cultura material, em que os bens representam a corrente entre produção e o consumo. Os bens de consumo começam a passar da ordem do físico para o "não físico" ou “desmaterializado".

A cultura material do consumo parece ser o ponto de referência ideal para se encaixar no contínuo fetichismo da mercadoria, não só em um nível teórico (ex. Spyer, 1997), mas também em um nível prático de tentar considerar quais transformações em conhecimento e produção são necessárias para fazer os consumidores reconhecerem os produtos que compram como, entre outras coisas, a corporificarão do trabalho humano. (MILLER, 2007, p.52)

Para acompanhar a tecnologia e a velocidade com que acontecem as transformações de consumo, as empresas pensam constantemente em diferentes opções para o consumidor. Hoje, um produto pode ser considerado moderno, mas, passando algum tempo, já aparece outro com tecnologia mais avançada, ou ainda com um recurso que o produto anterior não oferecia ao mercado. Esse mecanismo gera o descarte de produtos em curto espaço de tempo, mas o que fazemos com eles? Tantos bens são produzidos e descartados por perderem sua funcionalidade em um novo contexto.

Eis então que temos a internet como plano de fundo, mudando a relação do consumo e da materialidade dos objetos. "Consumir algo é usar algo, na realidade, destruir a própria cultura material” (MILLER, 207, p.34). Se por um lado a indústria teme a efemeridade de seus produtos e até mesmo a diminuição material deles, passamos por uma época em que adquirir produtos necessariamente não significa ter o contato físico com eles. A relação entre se ter um produto está relacionada ao acesso que o consumidor tem a ele ou ao benefício adquirido, o que necessariamente não corresponde a sua materialidade.

A indústria da música é um bom exemplo dessa transformação. Comprávamos compact discs e fitas de áudio até pouco tempo atrás, embora ainda existam no mercado, e hoje substituímos estes bens por arquivos de músicas digitais, além da possibilidade de 
comprarmos apenas uma música de cada álbum. Essa transformação vai do consumidor para indústria, pois a internet facilita a troca de músicas, até gratuitamente. Por que então o consumidor precisa comprar 12 músicas se gosta apenas de uma delas? Esse é o primeiro aspecto favorável ao mercado de nicho. Por que então não comprar várias músicas de cantores diferentes e compor uma playlist personalizada no iTtunes? A Apple e inúmeras outras empresas já oferecem customizações na aquisição de produtos voltadas ao mercado de nicho.

$\mathrm{O}$ estudo do comportamento do consumidor mostra-nos que existem diversas variáveis que podem interferir no comportamento de compra (SOLOMON, 2002), e que nem sempre o fator preço é a chave dessas decisões: pode-se citar ainda a qualidade, conveniência, marca, funcionalidade, moda, entre outros. O mercado de nicho pode oferecer bens segmentados, ter o produto certo para a pessoa certa, já que a comercialização segue os princípios da "Cauda Longa". (ANDERSON, 2009)

Baseado no resgate teórico apresentado neste artigo propõe-se a reflexão do consumo sob as seguintes variáveis: "sociedade do consumo" (BAUDRILLARD, 2003) que deseja e consome produtos dos mais diversos, "cultura material” (MILLER, 1998) com o acúmulo e o uso dos produtos de consumo, "efemeridade" (LIPOVETSKY, 1987) no que se refere às necessidades e desejos de consumo acompanhando as novas ofertas de mercado e o "descarte de produtos" (SOLOMON, 2002) como uma consequência ao desuso e do próprio ciclo de consumo. Chega-se então, ao termo "desmaterializado" referenciando a categoria de produtos que podem se ofertados para consumo sem necessariamente apresentar a exigência da aquisição física.

As indústrias da música e de filmes já utilizam arquivos virtuais como produtos comercializados e certamente novos produtos poderiam pensar em aproveitar o custo e o benefício da desmaterialização, que além de seguirem a tendência de mercado, estariam contribuindo para a diminuição do descarte de produtos físicos.

No processo de locação de filmes e seriados ofertados pela empresa Netflix, objeto empírico deste estudo, ocorre o desuso de matérias primas como sacolas, DVDs e embalagens, oferecendo sustentabilidade no processo no que se refere à diminuição do uso de recursos ambientais, além da adequação do canal de vendas ao perfil de determinados consumidores do mercado de nicho do consumo digital. Essa prática oferece comodidade no processo de aquisição dos bens, rapidez na entrega, ampla oferta de produtos, além de 
benefícios financeiros se comparado ao valor cobrado por serviço similar nas locadoras de vídeo.

Estimulando a desmaterialização dos produtos, têm-se vários benefícios agregados. Embora muito se fale em preservação ambiental, percebem-se tímidas ações que mostram tal atitude nas empresas, seja por receio do posicionamento do consumidor ou até mesmo por políticas internas.

Ao consumir, também se pensa, se reelabora o sentido social, é preciso se analisar como esta área de apropriação de bens e signos intervêm em formas mais ativas de participação do que aquelas que habitualmente recebem o rótulo de consumo. Em outros termos, devemos nos perguntar se ao consumir, não estamos fazendo algo que, nutre e, até certo ponto, constitui uma nova maneira de sermos cidadãos. (CANCLINI, 2008, p.42)

O uso de produtos desmaterializados mostra-se promissor sob vários aspectos sendo propiciador de uma sustentabilidade nos processos de aquisição de produtos e pode auxiliar no exercício da consciência ambiental nos indivíduos, além desta prática apresentar vantagens financeiras a quem consome. Outro ponto favorável seria a própria utilização do espaço físico: os ambientes e objetos estão cada vez menores incentivando a prática do não acúmulo de coisas, produtos virtuais ocupam espaços virtuais e contribuem para a adaptação nos meios físicos.

Observa-se, no entanto, a existência de barreiras no processo, pois o formato apresentado neste artigo para um consumo desmaterializado apropria-se da internet, que depende de outros fatores para se tornar viável, ao exemplo das barreiras financeiras, sociais e culturais advindas deste uso.

\section{4 - Netflix e o Comportamento e o Hábito de Consumo dos Filmes}

A fim de enriquecer a análise do objeto empírico deste artigo, utilizou-se o método de pesquisa não probabilística (ZIKMUND, 2005, p.69) para compreender o perfil de um grupo de respondentes em relação ao perfil de consumo de filmes e seriados. Estão entre as premissas, entender suas opiniões sobre as diferentes formas de consumo relacionadas às plataformas, aceitabilidade e conhecimento do Netflix e posicionamento sustentável em relação aos produtos que consomem. 
Parte-se do princípio que a Netflix é consumida por pessoas que possuem acesso à rede, uma vez que para a compra e o consumo do produto da empresa é necessária a posse de internet. Considerando os aspectos relacionados acima, optou-se por divulgar a pesquisa na rede social Facebook, por apresentar as características necessárias de consumidores em comum, pelo acesso aos computadores e a web, um indicativo de potencialidade de consumo para os produtos ofertados pela Netflix.

Para a realização da pesquisa optou-se pela utilização de dois métodos: o 'descritivo', que pretende “descrever as características de uma população ou de um fenômeno" (ZIKMUND, 2006, p.51) mapeando os hábitos de consumo do grupo e o 'causal', que será "conduzido para identificar as relações de causa e efeito entre as variáveis" (ZIKMUND, 2006, p.52), que pretende entender os direcionamentos pontuais em relação ao posicionamento dos entrevistados.

O método descritivo utilizou pesquisa survey qualitativa, aplicada eletronicamente por meio do uso da plataforma Google Docs e disponibilizada na rede Facebook em 17 de julho de 2012, permanecendo dois dias no ar com um total de 115 respondentes. O questionário foi constituído por vinte e três perguntas categorizadas por interesse de pesquisa, conforme mostra o gráfico 1 . O perfil do grupo foi de caráter misto e a pesquisa permitiu o compartilhamento do link de resposta entre outros grupos a fim do questionário ser propagado nas redes. Isso possibilitou a obtenção de um maior número de respondentes com características distintas, o que caracterizou a heterogeneidade do grupo e das respostas. Para a aplicação do método causal optou-se por incluir opções abertas de resposta, oportunizando a análise pontual dos comentários transformando-os em informações quantitativas e de relevância para a conclusão da pesquisa.

\section{Gráfico 1: Categorias da Pesquisa}

\begin{tabular}{|c|c|c|}
\hline Categorias de Pesquisa & $\begin{array}{c}\text { Número de } \\
\text { questões }\end{array}$ & Objetivo das perguntas \\
\hline Perfil Consumidor & 4 & Conhecer o perfil dos consumidores de filmes \\
\hline Hábitos de Consumo & 10 & $\begin{array}{l}\text { Entender o hábito de consumo de filmes } \\
\text { Entender com quem consomem filmes } \\
\text { Conhecer as plataformas de uso para assistir filmes seriados }\end{array}$ \\
\hline
\end{tabular}




\begin{tabular}{|l|c|l|}
\hline & & $\begin{array}{l}\text { Conhecer o valor pago pelos pesquisados nos serviços que } \\
\text { oferecem filmes e seriados }\end{array}$ \\
\hline Uso da Internet, Games e Netflix & 6 & $\begin{array}{l}\text { Detectar as formas de uso } \\
\text { Conhecer os consumidores da Netflix } \\
\text { Averiguar o conhecimento e opinião sobre a Netflix }\end{array}$ \\
\hline $\begin{array}{l}\text { Consciência Ambiental e } \\
\text { Desmaterialização no Processo de }\end{array}$ & 3 & $\begin{array}{l}\text { Entender a influência deste fator nos processos de consumo } \\
\text { de filmes } \\
\text { Mapear a aceitação na aquisição de produtos } \\
\text { desmaterializados }\end{array}$ \\
\hline
\end{tabular}

Fonte: Elaborado pela Autora

\section{1 - Perfil dos Consumidores}

A primeira parte do questionário visa mapear o perfil do consumidor de filmes e seriados. O grupo pesquisado foi representado por $63 \%$ do gênero feminino e $37 \%$ do masculino. Em relação à idade, 2\% possuem até 17 anos, 29\% de 18 a 24 anos, 38\% de 25 a 35 anos, $21 \%$ de 36 a 45 anos, $10 \%$ de 46 a 59 anos e $1 \%$ com mais de 60 anos. A maioria dos respondentes declarou ter o ensino superior completo e incompleto (51\%), seguindo de especialistas, mestres e doutores $(46 \%)$ e apenas 3\% com ensino médio completo ou incompleto. Do total de pesquisados, $100 \%$ declararam assistir filmes e seriados, o que demonstra a relação entre os consumidores que utilizam a internet/ redes sociais com o hábito de consumo de filmes.

\section{2 - Hábitos de Consumo}

Como segunda parte, buscou-se entender os hábitos dos consumidores de filmes e seriados em relação às práticas. Como plataformas de uso de consumo o resultado da pesquisa apontou a utilização de diversos canais com a proximidade de uso entre o cinema (88\%) e a televisão paga (80\%), mas apresenta um número bastante representativo de pessoas que baixam arquivos na internet por serviços gratuitos (57\%), comparado ao número de pessoas que baixam da internet com serviço pago (14\%), serviço em locadora (45\%) e até mesmo televisão aberta (37\%); conforme mostra o gráfico $2^{2}$.

\footnotetext{
${ }^{2}$ Questão múltipla: os índices podem ultrapassar $100 \%$.
} 


\section{Gráfico 2: Local em que costuma assistir/ ter acesso aos filmes e seriados.}

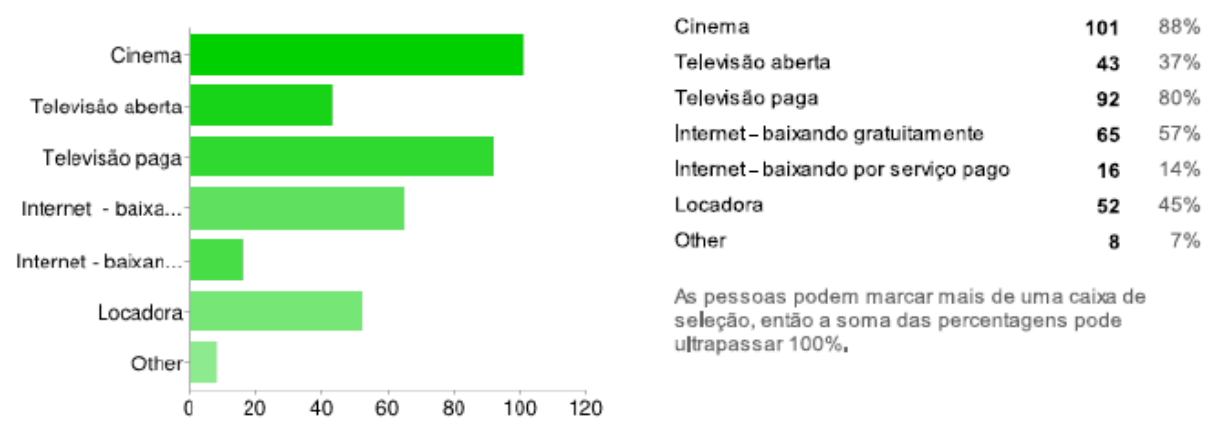

Fonte: Pesquisa quantitativa realizada pela autora

Complementando a questões acima, questionou-se aos respondentes qual dos locais apontados por eles, era o mais consumido apontando para a televisão paga (43\%) em primeiro lugar, seguido dos arquivos baixados por serviços gratuitos (29\%). Dos que marcaram a opção outros $(10 \%)$ encontrou-se como respostas o uso do DVD e do Youtube, conforme gráfico $3^{3}$.

\section{Gráfico 3: Das opções marcadas acima, qual utiliza com maior frequência para assistir filmes/ seriados.}

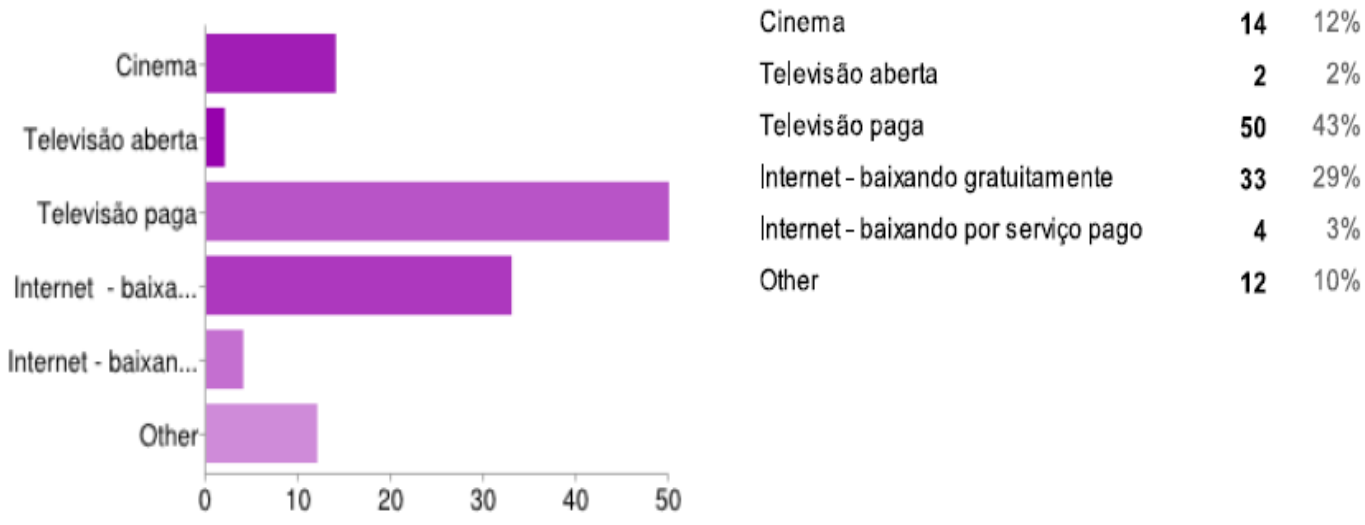

Fonte: Pesquisa quantitativa realizada pela autora

Como a principal variável na hora de escolher o local ou plataforma que assistem aos filmes e seriados os respondentes apontaram o quesito conveniência (61\%), seguido do ambiente (16\%), preço (10\%), companhia (10\%), tecnologia (2\%) e outros (1\%) que informaram ser o local. Com relação à escolha dos gêneros fílmicos os três mais citados

\footnotetext{
${ }^{3}$ Questão múltipla: os índices podem ultrapassar $100 \%$.
} 
foram: comédia (77\%), aventura (63\%) e ficção (53\%), conforme mostra o gráfico 3. Essa questão foi incluída na pesquisa pela necessidade de entendimento sobre o interesse por gênero, uma vez que o Netflix possui oferta restrita na categorização fílmica de documentários e filme arte, conforme mostra o gráfico 4.

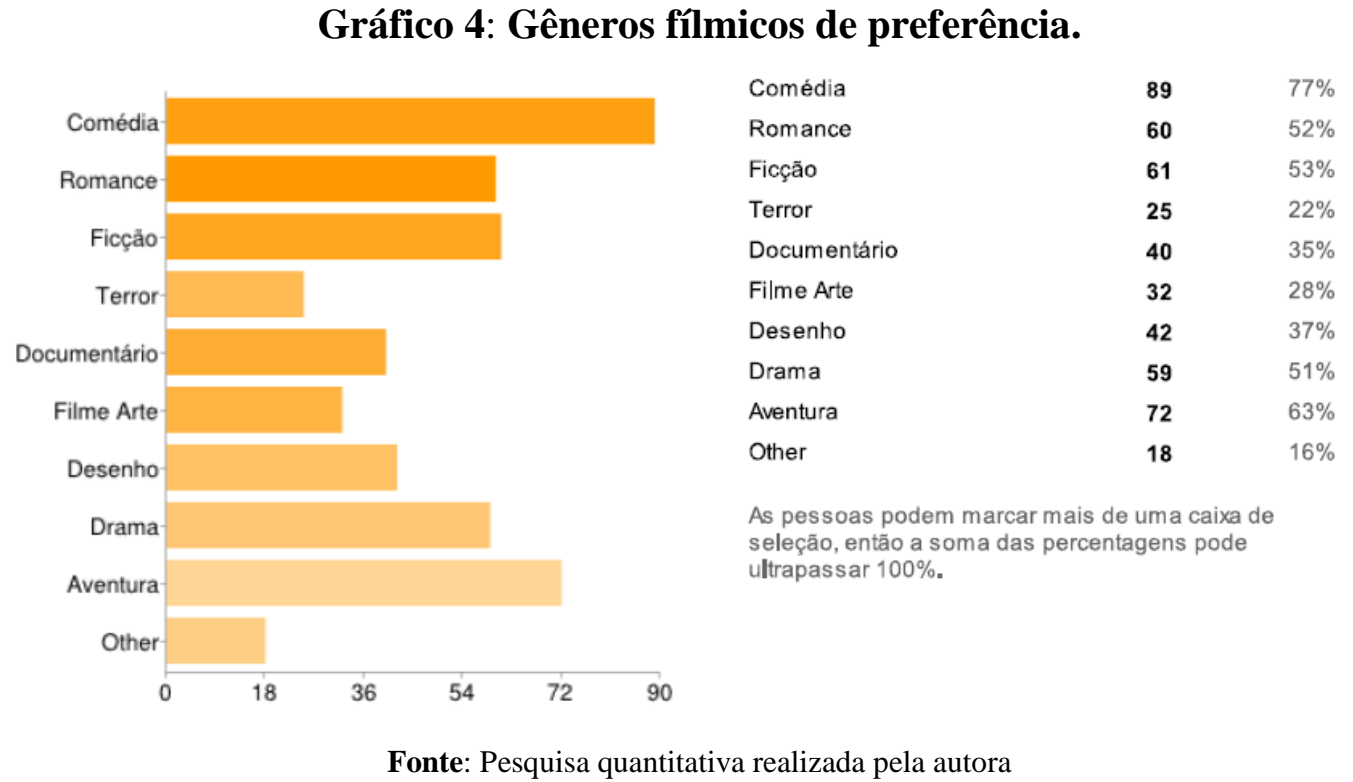

Sobre a quantidade de filmes assistidos por mês, $42 \%$ dos respondentes assistem de 5 a 10 filmes, $31 \%$ de 2 a 4 filmes, $22 \%$ mais de 11 filmes, sendo que apenas 5\% deles assistem 1 filme por mês. Ao serem questionados com quem assistem a seus programas, 44\% declararam assistir com o namorado (a), marido ou esposa, $26 \%$ sozinho, $18 \%$ com a família, 9\% com os amigos e 3\% com outras pessoas, cuja referência foi os filhos. Em relação aos hábitos de assistir seriados, $81 \%$ declararam assistir e $19 \%$ não assistem seriados. Ao serem questionados sobre qual o local que assistem aos filmes e seriados, a maioria indicou a televisão fechada (64\%), seguido de arquivos baixados na internet gratuitamente (48\%) e baixados na internet por serviço pago (10\%), conforme gráfico 5 . 


\section{Gráfico 5: Local que costuma assistir ou ter acesso aos seus seriados preferidos.}

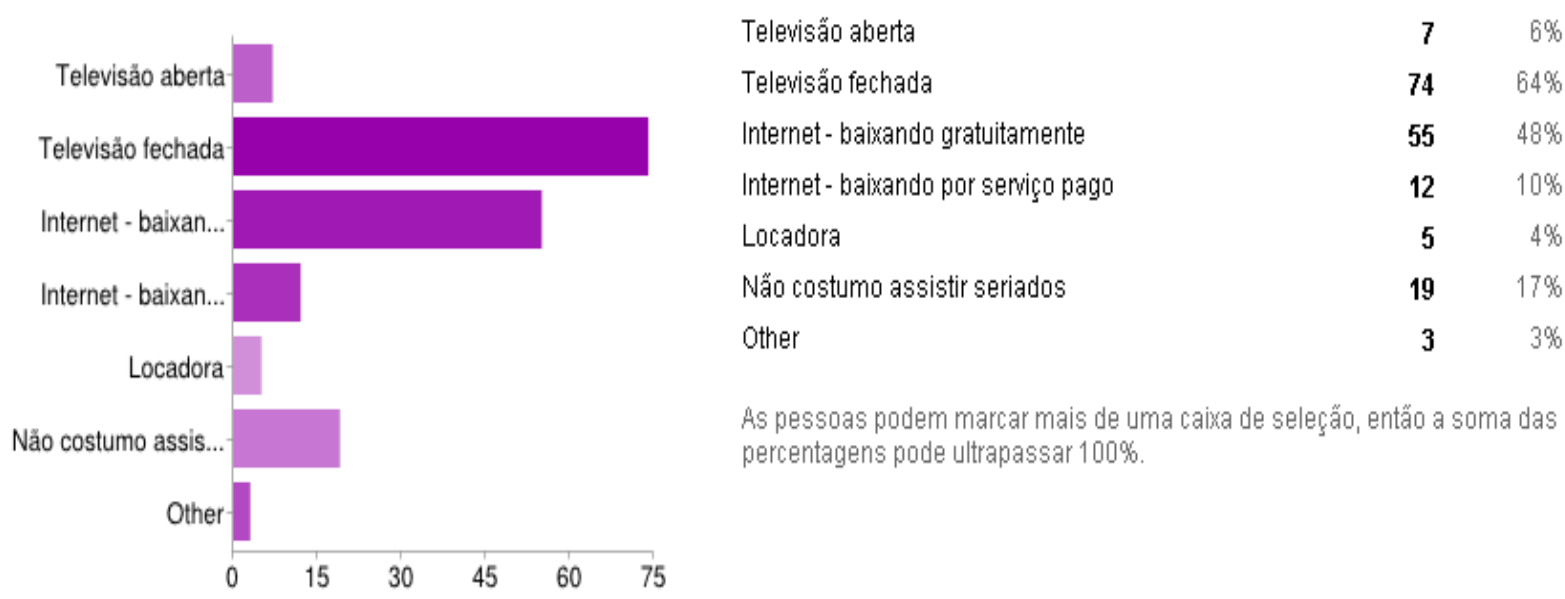

Fonte: Pesquisa quantitativa realizada pela autora

Sobre o valor pago para a locação de filmes e seriados, $42 \%$ dos respondentes não têm o costume de locar, 36\% paga entre $\mathrm{R} \$ 5,01$ a $\mathrm{R} \$ 10,00$ por locação, $18 \%$ até $\mathrm{R} \$ 5,00$ e $4 \%$ mais de $\mathrm{R} \$ 10,01$. Em relação ao pagamento das mensalidades de televisão fechada, $28 \%$ paga entre $\mathrm{R} \$ 70,01$ e $\mathrm{R} \$ 120,00,27 \%$ mais de $\mathrm{R} \$ 120,01,20 \%$ de $\mathrm{R} \$ 40,01$ a $\mathrm{R} \$ 70,00,20 \%$ não possuem televisão fechada e 5\% paga até R \$ 40,00 por mês.

4.3 - Hábitos de Uso da Internet, Games e Netflix

Nesta etapa buscou-se entender como o consumidor de filmes usa a internet no entretenimento. Ao serem questionados sobre baixarem arquivos de música e vídeo na internet, $73 \%$ declararam ter tal prática, contra $27 \%$ que não possuem o costume. Em relação à compra dos arquivos, $83 \%$ declararam não comprar contra $17 \%$ que adquirem o produto comercializado.

Sobre o uso de games, $52 \%$ dos respondentes declararam jogar games, contra $48 \%$ que não possuem tal prática. As plataformas citadas como as mais utilizadas para os jogos foram o computador (41\%) e celular (26\%), porém $46 \%$ dos entrevistados declararam não jogar games novamente nessa questão ${ }^{4}$. Interessante observar que na questão anterior o número de pessoas que responderam não jogar games é superior em $2 \%$. Pode-se atribuir a abertura das plataformas proporcionadas pela questão, pois nesta pergunta mostrou-se a

\footnotetext{
${ }^{4}$ Questão múltipla: os índices podem ultrapassar $100 \%$. 
diversidades de locais que um game poderia ser jogado, como em celulares e tablets, conforme mostra o gráfico 6.

\section{Gráfico 6: Plataformas que costuma jogar games.}

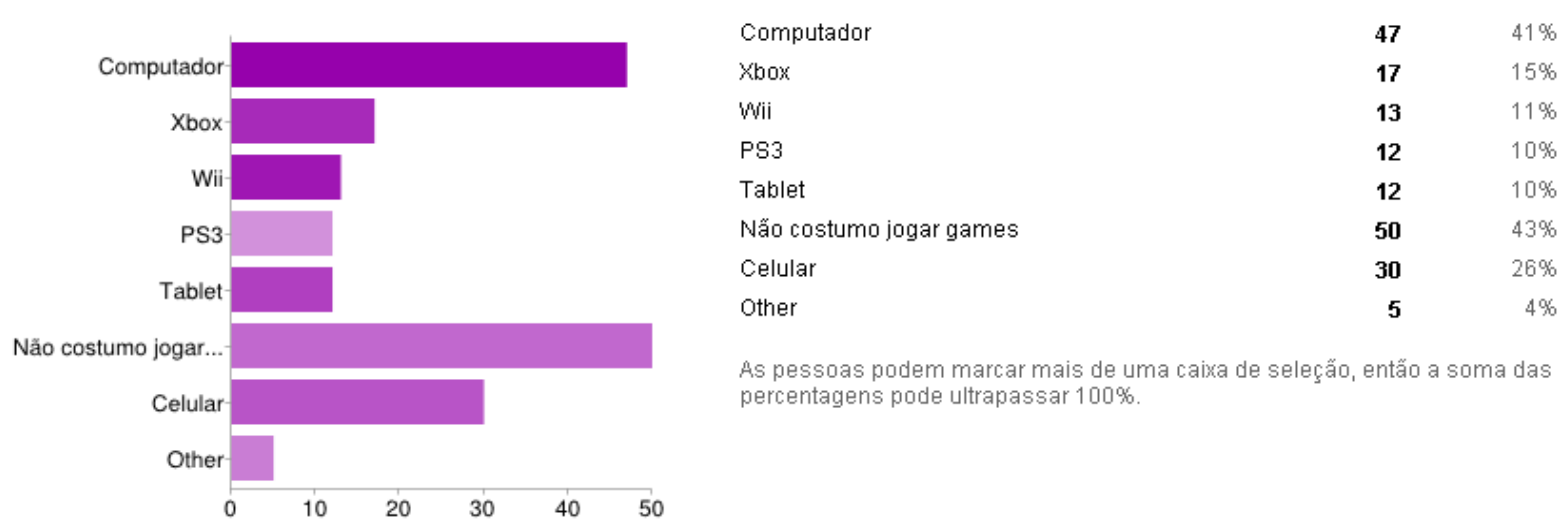

Fonte: Pesquisa quantitativa realizada pela autora

Em relação ao nível de conhecimento do produto oferecido pela Netflix, 67\% dos entrevistados já conheciam as ofertas contra 33\% que não as conheciam, sendo que apenas $21 \%$ já tinham comprado o produto, levando a conclusão de que $34 \%$ mesmo conhecendo, ainda não tinham consumido o produto.

Foram questionados ainda, se mudariam seus hábitos de consumo de filmes e seriados se a nova proposta de produto desmaterializado oferecesse atratividade financeira. Do total de respondentes, $83 \%$ se posicionaram favoravelmente, $12 \%$ negativamente e $5 \%$ marcaram outros, que inclui as seguintes opiniões: "meu hábito já é atrativo financeiramente", "depende do que eu perderia em qualidade" e "não é apenas o financeiro que conta". (GOOGLE DOCS/ PESQUISA, 2012).

\section{4 - Consciência Ambiental e Desmaterialização no Processo de Consumo}

$\mathrm{Na}$ última parte da pesquisa buscou-se a associação entre os novos tipos de comercialização dos filmes e seriados e o uso consciente dos recursos ambientais. Ao serem questionados sobre o consumo de produtos desmaterializados para ajudar o meio ambiente, $80 \%$ disseram que esses produtos ajudavam o meio ambiente, $17 \%$ declararam que não 
ajudavam e 3\% marcaram a opções outros, cujas respostas indicaram que o consumo consciente dependeria do contexto inserido; preço, oferta, qualidade e comodidade.

Em relação a se considerarem consumidores conscientes, no que se refere à preservação ambiental, $71 \%$ responderam ser conscientes, $21 \%$ que não são e $8 \%$ marcaram a opção outros, que consiste nos seguintes posicionamentos: "sei que sou muito consciente dos meus atos, porém sei que posso melhorar ainda mais", "depende" e "às vezes não consigo". (GOOGLE DOCS/ PESQUISA, 2012)

Por último, foram questionados se mudariam os hábitos de consumo de filmes e seriados se a atitude contribuísse para um consumo consciente. Do total de respondentes, $71 \%$ declararam que sim, $16 \%$ que não e $13 \%$ responderam à opção "outros”, cujas respostas serão detalhadas na análise qualitativa.

\section{4-5 Observações da Pesquisa Qualitativa}

Devido à necessidade de maior entendimento em relação ao tema da pesquisa, utilizaram-se dois pontos para a análise qualitativa das respostas: o uso dos comentários registrados nas questões abertas, que visavam à compreensão da aceitação do Netflix e a avaliação dos comentários registrados nas opções "outros", disponível nas questões que referenciavam a mudança no comportamento de consumo.

Para a análise do Netflix utilizou-se o método de pesquisa por palavras e definições com maior relevância e repetição entre os 115 respondentes, que permitiu a criação de interpretação qualitativa baseada em $\operatorname{Tag} \mathrm{Crowd}^{5}$ originando o gráfico 7. As palavras mais citadas para qualificar o serviço foram: "desconheço", "filme velho", "interessante", "preço bom”, "prefiro gratuito", “ótimo", "não uso" e "conveniente”.

\footnotetext{
${ }^{5}$ Nuvem de Palavras disponível em: http://tagcrowd.com/ 


\section{Gráfico 7: Tag Crowd para a questão aberta: Opinião sobre a Netflix}

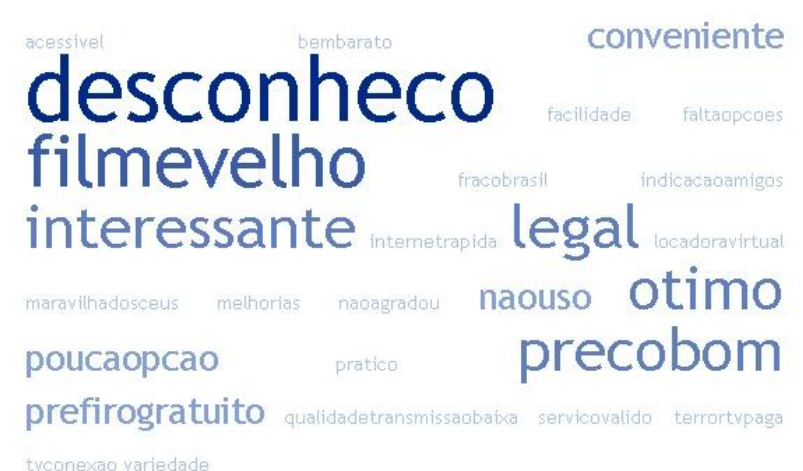

Fonte: Respostas qualitativas, elaborado pela autora

Para ilustrar as menções das opções "outros" nos itens que questionavam mudança de hábito de consumo por atratividade financeira ou consciência ambiental o método será a transcrição das citações para posterior análise.

\section{Gráfico 8: Mudança no Hábito de Consumo de Filmes e Seriados}

\begin{tabular}{|c|c|c|}
\hline $\begin{array}{c}\text { Mudança } \\
\text { por: }\end{array}$ & $\begin{array}{c}\text { Perfil do } \\
\text { Respondente }\end{array}$ & Respostas \\
\hline $\begin{array}{l}\text { Atratividade } \\
\text { Financeira }\end{array}$ & $\begin{array}{l}\text { Mulher/ } 36-45 \text { anos } \\
\text { Homem/ } 18-24 \text { anos } \\
\text { Mulher/ } 46-59 \text { anos } \\
\text { Mulher/ } 18-24 \text { anos } \\
\text { Homem/ } 36-45 \text { anos }\end{array}$ & $\begin{array}{l}\text { "Meus hábitos já são atrativos financeiramente". } \\
\text { "Depende de quanto à qualidade seria adquirida ou perdida". } \\
\text { "Não é só o financeiro que conta". } \\
\text { "Depende, não é só apenas o benefício financeiro que conta". } \\
\text { "Não só financeiro, mas qualidade também". }\end{array}$ \\
\hline $\begin{array}{l}\text { Forma de } \\
\text { Consumo } \\
\text { Consciente }\end{array}$ & $\begin{array}{l}\text { Homem/ } 25-35 \text { anos } \\
\text { Homem/ até } 17 \text { anos } \\
\text { Mulher/ } 25 \text { - } 35 \text { anos } \\
\text { Homem/ } 18-24 \text { anos } \\
\text { Mulher/ } 46-59 \text { anos } \\
\text { Mulher/ } 36-45 \text { anos } \\
\text { Mulher/ } 18-24 \text { anos }\end{array}$ & $\begin{array}{l}\text { "Talvez, depende da proposta da marca". } \\
\text { "Se tiver um preço que vala apena, sim". } \\
\text { "Dependeria do custo benefício". } \\
\text { "Dependeria de quanto à qualidade seria adquirida ou perdida". } \\
\text { "Nunca pensei sobre isso". } \\
\text { "Depende do preço, pois o que vejo é que na maioria dos } \\
\text { produtos ditos como sustentáveis ou de consumo consciente são } \\
\text { mais caros que os demais". } \\
\text { "Depende, atualmente não tenho boas condições financeira. } \\
\text { Não sendo muito caro, sim". }\end{array}$ \\
\hline
\end{tabular}

Fonte: Pesquisa dados qualitativos, realizada pela autora 


\section{4-6 Conclusões Apontadas pela Pesquisa}

Após a análise dos dados quantitativos e qualitativos, percebe-se a intenção dos usuários de internet em utilizar serviços que disponibilizam filmes e seriados na plataforma $w e b$, no entanto, ainda existem apontamentos de conservadorismo ou motivos para a não mudança de alguns hábitos cotidianos.

Segundo dados encontrados na pesquisa, o cinema e a televisão aberta perdem espaço para a televisão paga e internet, pelo próprio dinamismo e customização que oferecem em suas programações. Observa-se aqui, que todos os meios citados para entrega de áudiovisual, com exceção a locação de filmes em DVDs, são produtos entregues de forma desmaterializadas com maneiras diferenciadas de uso. A televisão paga já oferece a customização das programações por meio do pay per view, mas que ainda só é possível acesso aos assinantes mensais, o que onera investimento e adesão aos planos ofertados.

A comodidade, diversidade de escolhas, customização, qualidade e o preço, foram os principais fatores apontados na pesquisa, no qual gera expectativas em conjunto no momento da escolha do que consumir. Embora a maioria (73\%) declarou baixar vídeos pela internet, um número considerável destes consumidores (58\%) ainda possuem o costume de locar vídeos fisicamente, o que mostra a tendência ao uso de produtos materiais neste segmento, embora se perceba que em várias situações durante a pesquisa demonstraram interesse nos produtos desmaterializados. Os consumidores já assistem vídeos pela internet, mostrando mudança comportamental neste hábito, impulsionados pelas facilidades da convergência tecnológica no consumo deste segmento.

Os gêneros fílmicos escolhidos pelos respondentes são os mais variados, reforçando a ideia do mercado de nicho: sempre terá um consumidor para um determinado tipo de produto e as marcas podem se especializar em nichos o que torna o mercado mais aberto, já que os consumidores são diferentes e querem ser tratados assim. A presença de usuários de games em diversas plataformas, também possui representatividade no grupo de respondentes. Vale lembrar que o grupo foi heterogêneo representado por participantes de diversas idades e gêneros. Se a pesquisa fosse realizada pelo cruzamento de targets, os resultados sofreriam alterações. 
Em relação ao conhecimento da empresa Netflix, embora $67 \%$ dos entrevistados já conhecessem o produto, apenas $21 \%$ tinham experimentado. Também sobressai nos resultados, que a maioria dos respondentes que baixa arquivos da internet não paga por eles. Avaliando as questões abertas, os pesquisados demonstraram acreditar na gratuidade dos conteúdos, o que se torna um desafio, uma vez que as práticas de download nem sempre são legais.

Em relação ao uso consciente dos produtos, $80 \%$ declararam acreditar que consumir produtos desmaterializados ajuda a preservar o meio ambiente e $71 \%$ disseram ter consciência de suas escolhas em relação à preservação ambiental. Contudo, deixaram claro nas questões qualitativas que suas escolhas não são pautadas por este fator, representando uma descoberta considerável na pesquisa. Os fatores pontuados foram: preço, qualidade e comodidade, que também são levados em conta no momento da compra.

\section{Considerações}

O tema deste artigo apresentou reflexões sobre a forma com que consumimos produtos na contemporaneidade. Com a evolução tecnológica, em grande parte das áreas do conhecimento, já é possível utilizarmos diferentes recursos com a finalidade de diminuir a produção dos bens físicos, gerando um menor descarte dos mesmos e ainda, proporcionar uma atitude sustentável preservando o que extraímos do meio ambiente. $\mathrm{O}$ uso da tecnologia na mediação de produtos desmaterializados é visto como uma tendência no que se refere à utilização destes recursos em prol a diminuição do número de objetos criados pela humanidade, além da própria agilidade e acessibilidade nos processos de consumo.

A convergência de meios mostra-se promissora no cenário atual do consumo, no qual os indivíduos buscam alternativas das mais variadas a fim de acessar conteúdos personalizados pelos aparelhos na hora que desejarem e quando desejarem, isso caracteriza, ainda mais, a necessidade de criação de produtos voltados à utilização na web. As empresas buscam inovar seus produtos e ofertarem-nos em diversos aparelhos, como é o caso da Netflix que oferece filmes para consumo em vídeo games. 
O mercado de nicho é favorável à oferta de produtos diferenciados, que não visam o consumo pela grande massa, mas que conquistam parcelas pequenas de consumidores com características em comum. Em algumas situações o consumidor está disposto a pagar um valor diferenciado por um serviço customizado, desde que possa usufruir integralmente.

Como o intuito de averiguar o entendimento e aceitação da Netflix junto aos consumidores do mercado de nicho, especificamente aos que utilizam redes sociais, aplicouse a pesquisa empírica em um grupo de pessoas no Facebook. A pesquisa abordou questionamentos sobre variações tecnológicas, financeiras, de produto e relação com a sustentabilidade. Os dados da pesquisa mostraram a ocorrência de um conservadorismo por parte dos respondentes que, ao mesmo tempo, gostam de escolher os filmes pela oferta da empresa, mas continuam utilizando as televisões pagas e vídeo locadoras para acessar seus conteúdos preferidos.

Percebeu-se pelo resultado apresentado, que, embora todos os respondentes assistissem filmes e seriados, os hábitos já estão sendo alterados gradativamente mostrando divergência entre consumidores com perfis similares. A conveniência e o acesso à informação ilimitada foram as principais características presente na análise do comportamento destes pesquisados e as questões ambientais e preocupação com a sustentabilidade não se mostraram como foco de atenção em suas escolhas.

Para continuação deste estudo, pretende-se cruzar os dados transversais da pesquisa na tentativa de separar os respondentes em clusters estabelecendo nichos de mercados. Temse como hipótese que clusters apresentariam tendências comportamentais, no que se refere ao uso de produtos desmaterializados, até pela própria diferença no uso da internet.

A indústria vem buscando a diminuição de objetos, por representar algo moderno, por ser o que o consumidor procura e essa postura remete-nos a reflexão sobre o próprio descarte dos produtos, criam-se mais e mais coisas que já nascem fadadas ao desuso. A barreira para este novo olhar do consumo é voltada à própria aceitação social do consumidor, que, está em constante adaptação e que leva um tempo para o novo modo ser incorporado, como percebido na pesquisa empírica.

O desafio do mercado é se preparar para oferecer produtos que atendam às demandas específicas dos nichos com usos dos mais variados de forma customizada, com qualidade, e acima de tudo, pensar em como seus bens podem ser sustentáveis. Talvez não seja possível 
fazer isso com todos os produtos, mas se uma parcela das empresas já o fizer, estaremos iniciando o processo de produção e consumo consciente. É preciso que todos os evolvidos no processo de consumo alinhem seus interesses na direção da sustentabilidade ambiental.

O consumidor, por outro lado, está disposto a adquirir produtos sustentáveis, mas não considera que deve pagar mais por isso. Se a indústria produzir mais produtos desmaterializados, certamente terá a oportunidade de oferecer por valores similares aos materiais, ou até mesmo mais acessíveis, que farão com que, aos poucos, os consumidores de habituem com as novas formas de consumo, que já vem ocorrendo na indústria de livros, por exemplo.

Produtos desmaterializados auxiliam também nas questões de armazenamento, pois nos adaptamos a ambientes cada vez menores, a praticidade e a mobilidade. Os produtos desmaterializados ofertados na web podem ser armazenados e transportados em arquivos digitais, como exemplo os arquivos de música, e ainda, este tipo de produto auxilia ao não acúmulo de lixos físicos, o que geraria novas discussões principalmente no que se refere às questões de saúde pública, principalmente voltado às minorias.

O marketing e a publicidade, incorporando tais benefícios, estariam contribuindo ao processo de prática da cidadania e ao ensino. O desafio é criar mecanismos para que as empresas desenvolvam estratégias lucrativas nessa linha, que favoreçam de forma igualitária a cadeira de produção e de consumo e que tragam inovações no uso das mais variadas plataformas e suas possibilidades de acesso e consumo.

\section{Referências}

ANDERSON, Chris. A Cauda Longa. Do mercado de Massa ao Mercado de Nicho. São Paulo: Editora Campus, 2009.

BARBOSA, Lívia; CAMPBELL, Colin. Cultura, consumo e identidade. Rio de Janeiro: Editora FGV, 2006.

BAUDRILLARD, Jean. A sociedade de consumo. Lisboa: Edições 70 Editora, 2003.

CANCLINI, Nestor Garcia. Consumidores e cidadãos. Conflitos Multiculturais da Globalização. Rio de Janeiro: Editora UFRJ, 3 edição, 1995. 
CASTELLS, Manuel. A sociedade em rede. A era da informação. Economia, Sociedade e Cultura. Volume I. São Paulo: Paz e Terra, 6 edição, 2009.

CASTELLS, Manoel. Sociedade em Redes. Do conhecimento a ação política. Disponível em: $<$ http://www.egov.ufsc.br/portal/sites/default/files/anexos/a_sociedade_em_rede__do_conhecimento_a_acao_politica.pdf\#page=16>. Acesso em 15/07/2012, 2002.

EXAME. Suécia é o país mais conectado. Brasil é o 72. Disponível em: $<$ http://exame.abril.com.br/tecnologia/noticias/suecia-e-o-pais-mais-conectado-brasil-e-o-72oveja-o-mapa?utm_source=newsletter\&utm_medium=e-mail\&utm_campaign=newsdiaria.html>. Acesso em 07/08/2012.

FACEBOOK. Rede Social Facebook. Disponível em: www.facebook.com. Acesso $17 / 07 / 2012$

GOOGLE DOCS/PESQUISA. Plataforma de Gerenciamento e Monitoramento de Dados. Disponível em: www.docs.google.com>. Acesso em 15/07/2012.

IBGE. Instituto Brasileiro de Geografia e Estatística. Disponível em: <www.ibge.org.br>. Acesso em 14/07/2012.

JENKINS, Henry. Cultura da convergência. São Paulo: Editora Aleph, 2008.

KOTLER, Philip; ARMSTRONG, Gary. Princípios de marketing. São Paulo: Editora Prentice Hall, 7 edição, 1998.

LIPOVETSKY, Gilles. O império do efêmero. A moda e seu destino nas sociedades modernas. São Paulo: Companhia das Letras, 1987.

MILLER, Daniel. Teoria das compras. O que orienta as escolhas dos consumidores. São Paulo: Nobel, 1998.

MILLER, Daniel. Consumo como Cultura Material. Revista Horizontes Antropológicos, Porto Alegre, ano 13, n. 28, p. 33-63, jul./dez. 2007. Disponível em: http://www.scielo.br/pdf/ha/v13n28/a03v1328.pdf. Acesso em julho 2012.

MOWEN, John; MINOR, Michael S. Comportamento do Consumidor. São Paulo: Person Prentice Hall, 2003.

NETFLIX. Empresa Netflix. Disponível em:<www.netflix.com/Brasil>. Acesso em maio de 2012.

SOLOMON, Michael R. Comportamento do consumidor. Comprando, possuindo e sendo. Tradução Lene Belon Ribeiro. Porto Alegre: Bookman. 5 edição, 2002. 
TAG CROWD. Relevância de termos em pesquisa. Disponível em: http://tagcrowd.com/. Acesso em: Julho 2012.

UOL. Brasil tem mais de 250,8 milhões de linhas ativas de celulares. http://olhardigital.uol.com.br/negocios/digital_news/noticias/brasil-tem-mais-de-250,8milhoes-de-linhas-ativas-de-celulares. Acesso em 10/07/2012.

ZIKMUND, William G. Princípios da Pesquisa de Marketing. São Paulo: Pioneira Thomson Learning, 2 edição, 2006.

Original recebido em: 30/10/2012

Aceito para publicação em: 03/12/2012

Resumo sobre o autor

Letícia Salem Herrmann Lima. é doutoranda em Comunicação e Linguagens na Universidade Tuiuti do Paraná, Professora dos cursos de Graduação em Publicidade e Propaganda e Marketing na UFPR, UTP, UNICURITIBA, Pós Graduação em Mídia Digital e Marketing na UTP e Analista de Pesquisa de Mercado no Marknet /UTP. 